\title{
The significance of Survivin and Nectin-4 expression in the prognosis of breast carcinoma
}

\author{
Anna Maria Athanassiadou, Efstratios Patsouris, Angelos Tsipis, Maria Gonidi, \\ Pauline Athanassiadou
}

\author{
$1^{\text {st }}$ Pathology Laboratory, Cytology Unit, Medical School, University of Athens, Athens, Greece
}

\begin{abstract}
To investigate the prognostic significance of Survivin and Nectin-4 expression in breast carcinomas. Imprint smears were obtained from 140 breast carcinoma specimens and studied immunocytochemically for the expression of Survivin and Nectin-4. The results were correlated with several clinicopathological parameters, including five-year survival. Increased Survivin staining pattern correlated with increased grade $(\mathrm{p}<0.0001)$, increased lymph node invasion ( $\mathrm{p}<0.0001)$, increased tumor size and reduced survival $(\mathrm{p}<0.0001)$. Elevated Nectin-4 expression also correlated significantly with increased grade $(\mathrm{p}<0.0001)$, increased tumor size $(\mathrm{p}<0.0001)$ and reduced survival $(\mathrm{p}<0.0001)$. In addition, Survivin and Nectin-4 staining patterns correlated strongly with one another $(\mathrm{p}<0.0001)$. However, on multivariate analysis, neither Survivin nor Nectin-4 expression seemed to have an independent impact on survival in our study cases. The findings of our study suggest that increased expression of Survivin and Nectin-4 may indicate a worse prognosis in breast cancer patients. The exact implications of the expression of these markers in breast cancer prognosis and treatment remain to be clarified. (Folia Histochemica et Cytobiologica 2011; Vol. 49, No. 1, pp. 26-33)
\end{abstract}

Key words: breast cancer, Survivin, Nectin-4, immunocytochemistry, prognosis

\section{Introduction}

Breast cancer is a complex and heterogeneous disease at the molecular level. Therefore the emerging molecular classification of breast cancer is based on data obtained from gene and protein expression profiling.

Immunohistochemistry has helped in defining the molecular and prognostic signatures of breast cancer. Identifying new protein markers that help improve patient management is a priority in breast cancer research [1-6].

Survivin has been identified as a novel inhibitor of apoptosis. It blocks common downstream elements of both the mitochondrial pathway and the

Correspondence address: P. Athanassiadou,

Pathology Laboratory, Cytology Unit, Medical School,

University of Athens, Mikras Asias Str. 75,

GR-115 27 Athens, Greece;

fax: (+ 30 210) 74621 57; e-mail: pathanas@cc.uoa.gr death receptor pathway, by directly inhibiting terminal effectors caspases activity [7-10].

Survivin is expressed during embryonic and fetal development, but is undetectable in terminally differentiated normal adult tissue. However, it is re-expressed in human cancer cells at a frequency of $34-100 \%$ [11-13]. As a prognostic factor, Survivin expression is significantly associated with a poor clinical outcome in cancers including breast cancer [8, 14-18].

Nectins are cell adhesion molecules involved in the regulation of epithelial physiology. Four Nectins have been described so far. Nectin-4 is a new tumor-associated antigen and a reliable marker for breast carcinoma. Furthermore, it represents a sensitive and complementary marker for the follow-up of patients with metastatic breast carcinoma [19-21].

Our aim was to study the expression pattern of Survivin and Nectin-4 proteins in imprints of invasive breast carcinoma and their clinicopathological and prognostic value, as well as their relation to markers indicative of the tumor phenotype. 


\section{Material and methods}

One hundred and forty breast tumors, freshly resected from women who had undergone total mastectomy, were studied. Cytologic imprint smears were obtained by touching the cut surface of breast carcinoma tissues. One hundred and fifteen of the tumors were histologically ductal invasive of no special type, and 25 were lobular invasive carcinomas. The patients were aged from 28 to 85 years with a mean of 55.72 years. The histological diagnosis was determined during routine pathological assessment. The tumors were classified according to the histological typing of breast tumors by the WHO [22] and the tumors were graded according to the ScarffBloom Richardson classification as modified by Elston and Ellis [23]. Staging at the time of diagnosis was based on the TNM system [24]. Tumor size (less than $2 \mathrm{~cm}, 2$ to $5 \mathrm{~cm}$, more than $5 \mathrm{~cm}$ ) and lymph node status were evaluated separately. Additional information was recorded concerning the patient's menopausal status (ERa/PR) as determined immunohistochemically [23] and HER-2 expression. The clinicopathological characteristics of the patients are listed in Table 1. Follow-up was available for all 140 patients every three months post-operatively. The follow-up period was 60 months. At the end of those 60 months, $32(22.9 \%)$ patients had died of their disease and 108 patients had developed recurrence. Mean survival time was 36.71 months (range 5 to 60 months) and median survival time was 37.50 months. Patient outcome was defined as disease overall survival.

None of the patients had received radiation or chemotherapy preoperatively. After surgery, the patients received adjuvant therapy, depending on the extent of the disease, including anti-estrogen therapy and radiation therapy when indicated. Premenopausal patients with lymph nodes involvement were treated with four cycles of adjuvant chemotherapy using doxorubicin/cyclophosphamide followed by paclitaxel for four cycles.

Imprint smears were obtained from each patient by touching the cut surface of the freshly resected tumor tissues. We prefer to use imprint smears instead of paraffin-embedded tissue sections and cells (cell blocks), because the latter present difficulties with regard to immunoreactivity. Depending on the thickness of the section, there will always be a number of cells either sliced or overlapped, leading either to false low or to false high immunoreactivity, respectively [25-27]. Furthermore, tissue fixation and, to a lesser degree, tissue processing, are potential causes of variation in the reproducibility of immunohistochemical staining [28]. Above and beyond that, in cytologic preparations, the cells are whole, a larger surface of the tumor is sampled, and tissue is preserved for subsequent pathological and molecular analyses [27, 29-31]. It is now firmly established that a wide variety of markers can be applied on cytologic preparations and that immunocytochemistry correlates well with immunohistochemistry [32-36].

For immunocytochemistry 4 smears were fixed for 10 minutes in $5 \%$ buffered formalin and stored at $-70^{\circ} \mathrm{C}$ until used.

Immunostaining was performed by the Avidin-Biotin Complex immunoperoxidase method [37]. Smears were incubated for 45 minutes with a normal rabbit serum diluted 1:40 in PBS. Then the smears were rinsed in three changes of PBS for five minutes each and incubated overnight in Survivin (0-8 Santa Cruz Biotechnology, USA) at a dilution 1:50 and Nectin-4 antibody (AF2659 Browse by Molecule, USA) at a dilution of 1:100. After washing in PBS, the smears were incubated with rabbit anti-mouse biotinylated immunoglobulins diluted 1:200 followed by the ABC complex/HPR. Visualization was achieved by a final incubation in 3,3'-diaminobenzide tetrahydrochloride. The smears were counterstained with Mayer's hematoxylin. Known positive controls were also stained simultaneously. Negative controls were stained by omitting the primary antibodies incubation.

The results were interpreted by two independent cytologists by means of light microscopic observation. In cases where staining was heterogeneous in the slide, examined fields included those with the highest and those with the lowest percentage of stained cells. The score was the average of ten distinct high power fields observed at $\times 400$ magnification. Nuclear or cytoplasmic staining for Survivin and cytoplasmic staining for Nectin-4 were scored on a scale of zero to three, as follows: a score of 0 was given when there was no staining; a score of 1 if there was staining in less than $10 \%$ of cells; a score of 2 if there was moderate to strong staining in $11-50 \%$ of cells and a score of 3 if strong staining was detected in more than $50 \%$ of cells. For the purposes of statistical analysis, scores of 1, 2 and 3 were considered positive, and a score of 0 was considered negative (Figures 1,2).

Statistical analysis of the results was performed using Pearson's $\chi^{2}$ test. Survival curves were constructed with the use of the Kaplan-Meier method and compared using the log-rank test. Multivariate analysis was performed with the use of Cox's proportional hazard model. 


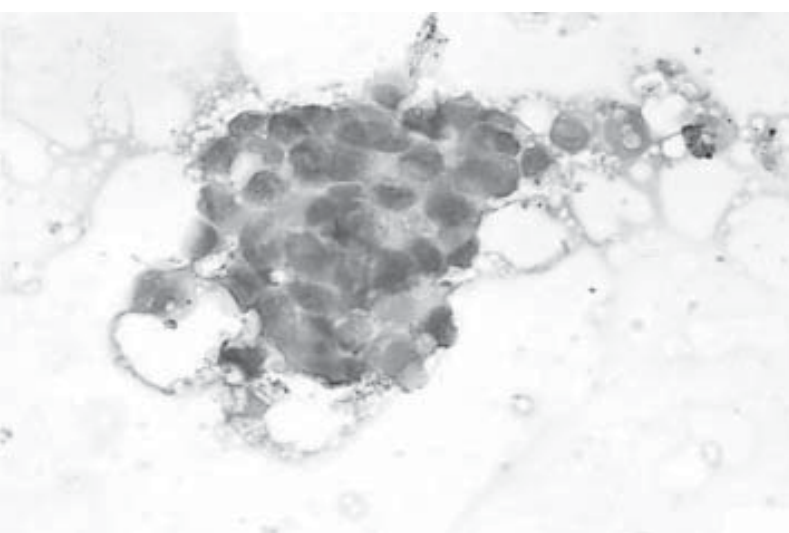

Figure 1. Breast adenocarcinoma cells with strong nuclear and mild cytoplasmic expression for Survivin (magnification $\times 500$ )

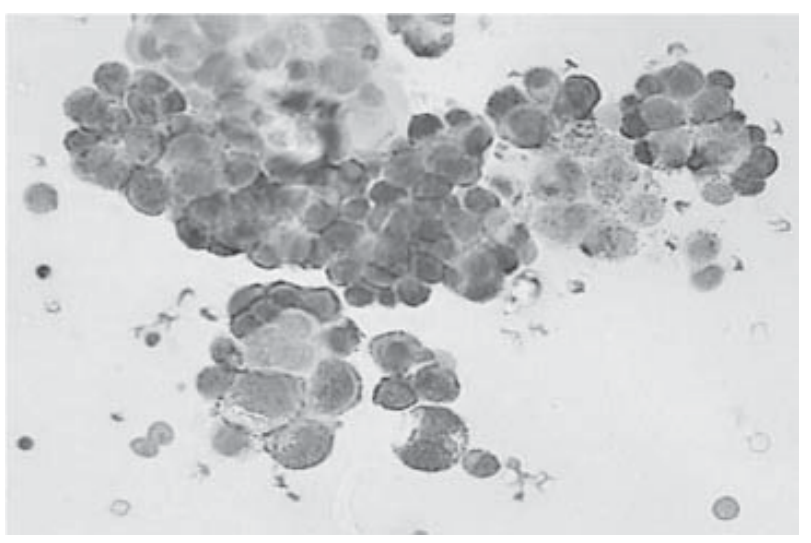

Figure 2. Clusters of breast adenocarcinoma cells with positive membrane and cytoplasmic expression for Nectin-4 (magnification $\times 500$ )

\section{Results}

Table 1 also provides the distribution of clinicopathological characteristics in the 140 breast tumors studied. Thirty eight women were premenopausal and 102 postmenopausal. Thirty five tumors were histological grade I, 40 grade II and 65 grade III. Tumor sizes were as follows: 37 were $\leq 2 \mathrm{~cm}, 78$ were $2-5 \mathrm{~cm}$, and 25 were $\geq 5 \mathrm{~cm}$. According to the number of positive nodes, four groups were formed $(0=35$ patients; $1-3=59$ patients; $4-9=37$ patients; and $>10=9$ patients) with positive lymph nodes. Of the 140 tumors, $90(64.3 \%)$ were ER and $80(57.1 \%)$ PR positive. HER-2 positivity was $31.4 \%$ as determined immunohistochemically.

Table 2 shows the distribution of Survivin and Nectin-4 staining pattern in all cases of breast carcinomas. Survivin was expressed in $65.7 \%$ and Nectin-4 in $64.3 \%$ of all tumors.

Survivin immunoreactivity was observed both in the cytoplasm and nuclear compartment of malig-

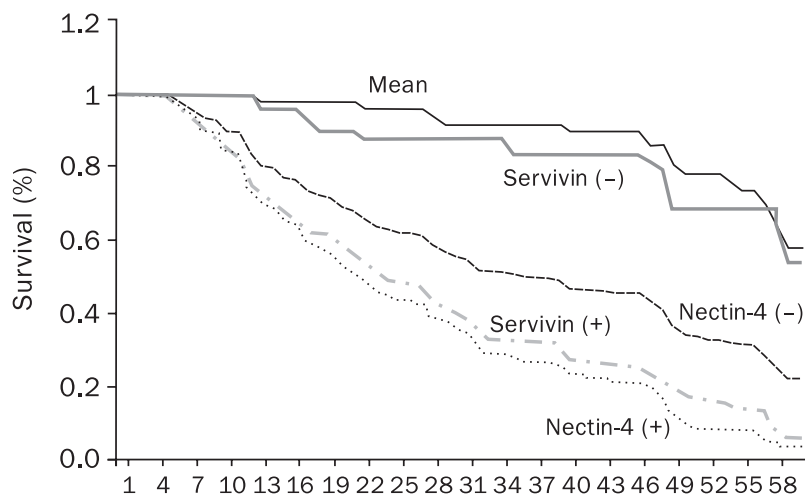

Figure 3. Overall survival curves according to Survivin and Nectin-4 expression

Table 1. Clinicopathological characteristics of patients

\begin{tabular}{|c|c|c|}
\hline Variables & Number & $\%$ \\
\hline \multicolumn{3}{|l|}{ Menopausal status } \\
\hline Premenopausal & 38 & 27.1 \\
\hline Postmenopausal & 102 & 72.9 \\
\hline \multicolumn{3}{|l|}{ Tumor size $(\mathrm{cm})$} \\
\hline$<2$ & 37 & 26.4 \\
\hline $2-5$ & 78 & 55.7 \\
\hline$>5$ & 25 & 17.9 \\
\hline \multicolumn{3}{|l|}{ Histological type } \\
\hline Ductal & 115 & 82.1 \\
\hline Lobular & 25 & 17.9 \\
\hline \multicolumn{3}{|l|}{ Histological grade } \\
\hline I & 35 & 25.0 \\
\hline II & 40 & 28.6 \\
\hline III & 65 & 46.4 \\
\hline \multicolumn{3}{|l|}{ Lymph nodes status } \\
\hline 0 & 35 & 25.0 \\
\hline $1-3$ & 59 & 42.1 \\
\hline $4-9$ & 37 & 26.4 \\
\hline$\geq 10$ & 9 & 6.4 \\
\hline \multicolumn{3}{|l|}{ ERa immunostatus } \\
\hline Negative & 50 & 35.7 \\
\hline Positive & 90 & 64.3 \\
\hline \multicolumn{3}{|l|}{ PR immunostatus } \\
\hline Negative & 60 & 42.9 \\
\hline Positive & 80 & 57.1 \\
\hline \multicolumn{3}{|l|}{ HER-2 } \\
\hline Negative & 96 & 68.6 \\
\hline Positive & 44 & 31.4 \\
\hline
\end{tabular}

nant cells or only in the cytoplasm or nucleus. Cytoplasmic Survivin immunoreaction was observed in $75 / 92(81.5 \%)$ cases, while nuclear was observed in $26 / 92(28 \%)$ cases. Twenty two $(23.9 \%)$ cases showed 
Table 2. Distribution of Survivin and Nectin-4 staining expression in 140 tumors of breast carcinoma

\begin{tabular}{|c|c|c|}
\hline Staining pattern & Frequency (No) & Percentage (\%) \\
\hline Survivin & & \\
Negative & 48 & 34.3 \\
Positive & 92 & 65.7 \\
\hline Nectin-4 & 50 & 35.7 \\
Negative & 90 & 64.3 \\
Positive & & \\
\hline
\end{tabular}

Survivin staining both nuclear and cytoplasmic compartment.

There seems to be no association between cytoplasmic and nuclear Survivin staining. However 7/12 $(58.3 \%)$ cases with very strong cytoplasmic intensity also showed nuclear staining. This was in contrast to only $17 / 63(26.9 \%)$ cases with lighter cytoplasmic staining $(\mathrm{p}=0.002)$. We failed to find any relationship between positivity rate of cytoplasmic or nuclear staining with all clinicopathological parameters analyzed. Moreover, no relationship was observed between cytoplasmic or nuclear Survivin staining with overall survival.

Therefore, a tumor was assessed as Survivin positive if the staining was positive cytoplasmic, or positive nuclear, or both. The results of $\chi^{2}$ analysis of the studied variables are summarized in Table 3 .

Survivin positive staining was significantly correlated with increased grade (III) $(\mathrm{p}<0.0001)$, increased number of lymph nodes invasion $(\mathrm{p}<0.0001)$ increased tumor size $(>2 \mathrm{~cm})$, negative ERa/PR status $(\mathrm{p}<0.0001$ respectively) and positive expression of HER-2 ( $\mathrm{p}<0.0001)$.

Similar associations were found for Nectin-4. Positive Nectin-4 expression was significantly associated with increased grade (II and III) ( $p<0.0001)$, increased tumor size $(\mathrm{p}<0.0001)$, negative ERa and PR status $(\mathrm{p}<0.0001)$ as well as with positive HER-2 expression $(\mathrm{p}<0.0001)$.

In addition, Survivin and Nectin-4 staining patterns correlated strongly to one another $(\mathrm{p}<0.0001)$.

We evaluated the association between Survivin and Nectin-4 expression and overall survival (Figure 3). Positive staining for Survivin and Nectin-4 was associated with lower five-year survival rates compared to negative staining $(6.5 \%$ vs. $54.2 \%$ and $3.3 \%$ vs. $58.0 \%)(\mathrm{p}<0.0001)$. A shorter survival was also strongly associated with higher grade of the tumor $(p<0.0001)$, increased number of lymph nodes invasion $(p<0.0001)$, positive expression of HER-2 $(\mathrm{p}<0.0001)$, and increased size of the tumor $>2 \mathrm{~cm}$ $(\mathrm{p}<0.0001)$ as well as with a negative ERa and PR status $(\mathrm{p}<0.0001)$. Further associations were demonstrated between Survivin and Nectin-4 staining respectively and the remaining clinical and pathological parameters examined.

The independent relationship of Survivin and Nectin-4 was studied with Cox multivariate regression analysis. We thus could establish whether the prognostic value of Survivin and Nectin-4 as found in univariate analyses could be attributed to its relationship with other clinicopathological factors, or whether Survivin and Nectin-4 contribute independently to prognosis. A multivariate analysis was performed, including age, menopausal status, nodal status, tumor size, histological type, ERa/PR status and HER-2. For overall survival, age $(\mathrm{p}<0.0001)$, grade $(\mathrm{p}<0.0001)$ and lymph nodes status $(\mathrm{p}<0.014)$ were significant (Table 4). Therefore, neither Survivin nor Nectin-4 expression seemed to have an independent impact on survival in our studied cases.

\section{Discussion}

Our study detected positive expression for Survivin in $65.7 \%$ of all breast carcinoma specimens. This percentage is within the range of previously published reports, in the majority of which positive Survivin expression is demonstrated with the use of immunohistochemistry [8].

The sub-cellular distribution of Survivin seems to be altered during the growth and progression of breast carcinoma, under the influence of yet unknown molecular mechanisms. However, the exact prognostic and clinical implications of the immunohistochemical localization (nuclear or cytoplasmic) of Survivin in different types remain controversial.

Our study found Survivin to be predominantly detected in the cytoplasmic compartment of breast cancer cells, confirming previous observations. Fortugno et al. showed that cytoplasmic and nuclear Survivin are immunocytochemically different, and this might partly explain the conflicting data on Survivin localization in solid tumors [38].

The relationship between immunocytochemical detected cytoplasmic and nuclear localization of Survivin has been not investigated. Although we found no relationship between cytoplasmic and nuclear staining, a high percentage of cases with very strong cytoplasmic intensity also showed nuclear Survivin immunoreaction $[15,39,40]$. In the literature, cytoplasmic expression of Survivin is reported to be a poor prognostic parameter in colorectal neuroblastoma, squamous cell and urothelial carcinoma. On the other hand, in studies of pancreatic, gastric, 
Table 3. Results of $\chi^{2}$ analysis showing the correlations between Survivin and Nectin- 4 staining patterns and several clinicopathological parameters in 140 patients with breast carcinoma

\begin{tabular}{|c|c|c|c|c|c|c|c|}
\hline \multirow[t]{3}{*}{ Variable } & \multirow[t]{3}{*}{ Total } & \multicolumn{6}{|c|}{ Staining pattern } \\
\hline & & \multicolumn{2}{|c|}{ Survivin } & \multirow{2}{*}{$\mathbf{p}$} & \multicolumn{2}{|c|}{ Nectin-4 } & \multirow[t]{2}{*}{$\mathbf{p}$} \\
\hline & & $(-)$ & $(+)$ & & $(-)$ & $(+)$ & \\
\hline Histology & 140 & & & & & & \\
\hline Ductal & & $41(25.7 \%)$ & $74(64.3 \%)$ & 0.465 & $42(36.5 \%)$ & $73(63.5 \%)$ & 0.669 \\
\hline Lobular & & $7(28.0 \%)$ & $18(72.0 \%)$ & & $8(32.0 \%)$ & $17(68.0 \%)$ & \\
\hline Grade & 140 & & & & & & \\
\hline I & & $27(77.1 \%)$ & $8(22.9 \%)$ & $<0.0001$ & $33(94.3 \%)$ & $2(5.7 \%)$ & $<0.0001$ \\
\hline II & & $20(50.0 \%)$ & $20(50.0 \%)$ & & $16(40.0 \%)$ & $24(60.0 \%)$ & \\
\hline III & & $1(1.5 \%)$ & $64(98.5 \%)$ & & $1(1.5 \%)$ & $64(98.5 \%)$ & \\
\hline Tumor size $[\mathrm{cm}]$ & 140 & & & & & & \\
\hline$<2$ & & $27(73.0 \%)$ & $10(27.0 \%)$ & $<0.0001$ & $28(75.7 \%)$ & $9(24.3 \%)$ & $<0.0001$ \\
\hline $2-5$ & & $21(26.9 \%)$ & $57(73.1 \%)$ & & $22(28.2 \%)$ & $56(71.8 \%)$ & \\
\hline$>5$ & & $0(0 \%)$ & $25(100 \%)$ & & $0(0 \%)$ & $25(100 \%)$ & \\
\hline Lymph nodes status & 140 & & & & & & \\
\hline 0 & & $27(77.1 \%)$ & $8(22.9 \%)$ & $<0.0001$ & $33(94.3 \%)$ & $2(5.7 \%)$ & $<0.0001$ \\
\hline $1-3$ & & $20(33.9 \%)$ & $39(66.1 \%)$ & & $17(28.8 \%)$ & $42(71.2 \%)$ & \\
\hline $4-9$ & & $1(2.7 \%)$ & $36(97.3 \%)$ & & $0(0 \%)$ & $37(100 \%)$ & \\
\hline$>10$ & & $0(0 \%)$ & $9(100 \%)$ & & $0(0 \%)$ & $9(100 \%)$ & \\
\hline $\mathrm{ER} \alpha$ status & 140 & & & & & & \\
\hline Negative & & $2(4.0 \%)$ & $48(96.0 \%)$ & $<0.0001$ & $7(14.0 \%)$ & $43(86.0 \%)$ & $<0.0001$ \\
\hline Positive & & $46(51.1 \%)$ & $44(48.9 \%)$ & & $43(47.8 \%)$ & $47(52.2 \%)$ & \\
\hline PR status & 140 & & & & & & \\
\hline Negative & & $2(3.7 \%)$ & $58(96.7 \%)$ & $<0.0001$ & $9(15.0 \%)$ & $51(85.0 \%)$ & $<0.0001$ \\
\hline Positive & & $46(57.5 \%)$ & $34(42.5 \%)$ & & $41(51.3 \%)$ & $39(48.8 \%)$ & \\
\hline $\begin{array}{l}\text { HER-2 } \\
\text { Expression }\end{array}$ & 140 & & & & & & \\
\hline Negative & & $48(50.0 \%)$ & $48(50.0 \%)$ & $<0.0001$ & $47(49.0 \%)$ & $49(51.0 \%)$ & $<0.0001$ \\
\hline Positive & & $0(0 \%)$ & $44(100 \%)$ & & $3(6.8 \%)$ & $41(93.2 \%)$ & \\
\hline Menopausal status & 140 & & & & & & \\
\hline Premenopausal & & $13(34.2 \%)$ & $25(65.8 \%)$ & $<0.991$ & $17(44.7 \%)$ & $21(55.3 \%)$ & 0.174 \\
\hline Postmenopausal & & $35(34.3 \%)$ & $67(65.7 \%)$ & & $33(32.4 \%)$ & $69(67.6 \%)$ & \\
\hline
\end{tabular}

Table 4. Cox's regression analysis of the prognostic value of the assessed variables with regard to overall survival

\begin{tabular}{|c|c|c|c|c|c|c|c|c|}
\hline & \multicolumn{8}{|c|}{ Variables in the equation } \\
\hline & \multirow[t]{2}{*}{ B } & \multirow[t]{2}{*}{ SE } & \multirow[t]{2}{*}{ Wald } & \multirow[t]{2}{*}{ df } & \multirow[t]{2}{*}{$\mathbf{p}$} & \multirow[t]{2}{*}{$\operatorname{Exp}(\mathbf{B})$} & \multicolumn{2}{|c|}{ 95\% CI for $\operatorname{Exp}(B)$} \\
\hline & & & & & & & Lower & Upper \\
\hline Age & 1.051 & 247 & 18.064 & 1 & 0.0001 & 2.861 & 1.762 & 4.646 \\
\hline Hist grade & 1.570 & 0.262 & 35.938 & 1 & 0.0001 & 4.806 & 2.876 & 8.029 \\
\hline LN status & 0.519 & 0.210 & 6.096 & 1 & 0.014 & 1.681 & 1.113 & 2.538 \\
\hline
\end{tabular}

SE - standard error; B - coefficient

urothelial and esophageal carcinomas, no association has been found between cytoplasmic Survivin and patient survival $[7,9,41,42]$.
The differential nuclear and cytoplasmic localization of Survivin is shown to be due to differences in the amino-acid sequence of its carboxy-terminal do- 
main [43]. Moon and Tornawski suggest the cytoplasmic localization of Survivin in non-malignant cells suppresses apoptosis, while its nuclear translocation may be important in the regulation of proliferation and differentiation [44].

In other studies of different types of cancers, the overexpression of Survivin correlates with increased proliferation, although the expression was cytoplasmic [43-46]. We believe that further studies designed to clarify the relationship between cytoplasmic and nuclear Survivin are needed in order to determine the role of Survivin detected immunocytochemically in cancer.

Our study found that Survivin positivity correlated with positive expression of HER-2 and lack of PR and ERa status. This is in agreement with other studies which have indicated that the Survivin protein positivity detected by immunohistochemical staining might be correlated with HER-2 expression but not with hormone receptors [47-49].

Furthermore, Survivin staining pattern correlated strongly with increased grade, increased tumor size, increased number of lymph nodes involvement, and reduced survival rates affecting the clinical outcome but as an independent parameter. In some studies it failed to demonstrate any association between Survivin positivity rate and the clinicopathological prognostic parameters in some solid tumors [43].

The possibility that the biological role of Survivin expression might also be influenced by tissue specificity cannot be ruled out and requires further attention.

In a study by Al-Joudi et al. it was found that negative and low expression of Survivin correlated significantly with favorable outcomes [8]. Conversely, high expression correlated with unfavorable outcomes $[8,17]$.

Also, experimental studies of different kinds of tumors have reported that overall survival is significantly decreased in patients with neoplasms expressing Survivin compared to those with no expression $[41,43,50,51]$.

Nectin-4 belongs to the family of cell adhesion molecules that regulate the formation of adherence functions in epithelial cells through the AF-6 afadin scaffold molecule [51-53]. Nectin-4 is an antigen mainly expressed during embryogenesis and highly expressed (68\%) in tumors of breast origin $[20,21]$. Nectin-4 staining has been described as prevalent cytoplasmic and discrete membrane stain [54-56].

In the present study, we detected positive expression for Nectin- 4 in $63.5 \%$ of all breast carcinoma specimens. This percentage is within the range of previously published results [20]. Fabre Lafay et al. reported positive expression of Nectin- 4 in $62 \%$ of ductal type and $6 \%$ of lobular type carcinomas, thus strongly correlating with histological type. Our study failed to reveal any difference in Nectin-4 expression rates among histological types of breast carcinoma. Moreover, Nectin-4 staining has been described as prevalent in the cytoplasm and membrane of malignant cells [20].

The same study found that ERa/PR negative tumors expressed Nectin-4. Furthermore, serum Nectin-4 is a marker of disease progression, metastatic status and clinical outcome of patients. No correlation was found between Nectin-4 and tumor size, tumor grade or lymph nodes status.

Nevertheless, univariate statistical analysis of our data showed a strong correlation between increased Nectin-4 staining pattern and the following adverse clinicopathological parameters: increased grade (II, III), increased tumor size, increased lymph nodes infiltration and reduced survival. These findings suggest that Nectin-4 overexpression may be a marker for a more aggressive clinical behavior and worse prognosis in breast carcinoma. However, the exact mechanism by which Nectin-4 contributes to cancer progression remains unclear.

We also found that the expression levels of Survivin and Nectin-4 correlated strongly to one another. The association of Survivin and Nectin-4 with unfavorable prognostic indicators, and with one another, as demonstrated in our study, suggests that these proteins may also interact in breast carcinoma in order to exert their adverse effect.

In conclusion, Survivin and Nectin-4 expression demonstrates a strong independent association with poor prognosis. It is possible that Survivin and Nectin-4 inhibitors may be of value in the treatment of breast cancer patients. For this reason, additional studies are needed to further define the prognostic importance of these markers. In addition, further molecular studies should determine the interactions that take place between Survivin and Nectin-4 during breast carcinogenesis, as well as their exact effect on the clinical outcome of patients.

\section{Conflicts of interest}

The authors declare that there are no conflicts of interest. 


\section{References}

1. Allred D, Harvey J, Berardo M, Clark G. Prognostic and predictive factors in breast cancer by immunohistochemical analysis. Mol Pathol. 1998;11:155-168.

2. Esteva F, Hortobagyi G. Prognostic molecular markers in early breast cancer. Breast Cancer Res. 2004;6:109-118.

3. Ross J, Linette G, Stec J et al. Breast cancer biomarkers and molecular medicine. Expert Rev Mol Diagn. 2000;3:573-585.

4. Gomulkiewicz A, Podhorska-Okolow M, Szulc R et al. Correlation between metallothionein (MT) expression and selected prognostic factors in ductal breast cancers. Folia Histochem Cytobiol. 2010;48:242-248.

5. Laudański P, Swiatecka J, Kozłowski L, Leśniewska M, Wojtukiewicz M, Wołczyński S. Increased serum level of membrane type 1-matrix metalloproteinase (MT1-MMP/MMP-14) in patients with breast cancer. Folia Histochem Cytobiol. 2010;48:101-103.

6. Agrawal AK, Jelen M, Rudnicki J, Grzebieniak Z, Zukrowski P, Nienartowicz E. Molecular markers (c-erbB-2, p53) in breast cancer. Folia Histochem Cytobiol. 2008;46:449-455.

7. Kawasaki H, Altieri DC, Lu CD, Toyoda M, Tenjo T, Tanigawa N. Inhibition of apoptosis by survivin predicts shorter survival rates in colorectal cancer. Cancer Res. 1998;58: 5071-5074.

8. Al-Joudi F, Iskandar Z, Hasman J et al. Expression of survivin and its clinicopathological correlations in invasive ductal carcinoma of the breast. Singapore Med J. 2007;48: 607-614.

9. La Casse E, Baird S, Korneluk R et al. The inhibitors of apoptosis (IAPs) and their emerging role in cancer. Oncogene. 1998; 17:3247-3259.

10. Reed JC. The survivin saga goes in vivo. J Clin Inves. 2001;108:965-969.

11. Ambrosini G, Adida C, Altieri DC. A novel anti-apoptosis gene, survivin, expressed in cancer and lymphoma. Nat Med. 1997;3:917-921.

12. Tanaka K, Iwamoto S, Gon G, Nohara T, Iwamoto M, Tanigawa N. Expression of survivin and its relationship to loss of apoptosis in breast carcinomas. Clin Cancer Res. 2000;6:127-134.

13. Izava A, Kobayashi $\mathrm{D}$, Nasu $\mathrm{S}$ et al. Relevance of c-erbB-2, PLU-1 and survivin mRNA expression to diagnostic assessment of breast cancer. Anticancer Res. 2002;22:2965-2969.

14. Span P, Sweep F, Wiegerinck E et al. Survivin is an independent prognostic marker for risk stratification of breast cancer patients. Clin Chem. 2004;50:1986-1993.

15. Adida C, Haioun C, Gaulard P et al. Prognostic significance of survivin expression in diffuse large B-cell lymphomas. Blood. 2000;96:1921-1925.

16. Fields AC, Cotsonis G, Sexton D, Santoianni R, Cohen C. Survivin expression in hepatocellular carcinoma: correlation with proliferation, prognostic parameters and outcome. Mod Pathol. 2004;17:1378-1385.

17. Kennedy SM, O’Driscoll L, Purcell R et al. Prognostic importance of survivin in breast cancer. Br J Cancer. 2003;88: 1077-1083.

18. Hinnis A, Luckett J, Walker R. Survivin is an independent predictor of short-term survival in poor prognostic breast cancer patients. Br J Cancer. 2007;96:639-645.

19. Raymold N, Fabre S, Lecocq E, Adelaide J, Dubreuil P, Lopez M. Nectin 4/PRR4, a new afadin-associated member of the nectin 1/PRR1 through V domain interaction.J Biol Chem. 2001;276:43205-43215.

20. Fabre-Lafay S, Monville F, Garrido-Urbani S et al. Nectin-4 is a new histological and serological tumor associated marker for breast cancer. BMC Cancer. 2007;7:73.
21. Takai Y, Irie K, Shimizu K, Sakisaka T, Ikeda W. Nectins and nectin-like molecules: roles in cell adhesion, migration and polarization. Cancer Sci. 2003;94:655-667.

22. Tavassoeli FA; Devilee P. Pathology and genetics: tumors of the breast and female genital organs. Lyon: WHO Press; IARC WHO Classification of Tumours, 2003;4.

23. Elston CW, Ellis I. Pathological prognostic factors in breast cancer I. The value of histological grade in breast cancer: experience from a large study with long-term follow up. Histopathology. 2002;41:154-161.

24. Union International Contre Cancer; International Union Against Cancer. In: Wittekind Ch, Hutter R, Greene FL, Klimpfinger M, Sobin LH (eds). TNM Atlas, $5^{\text {th }}$ edition. Springer-Verlag 2005.

25. Bantis A, Gianopoulos A, Gonidi M et al. Expression of pl20, $\mathrm{Ki}-67$ and PCNA as proliferation biomarkers in impact smears of prostate carcinoma and their prognostic value. Cytopathology. 2004;15:25-31.

26. Greene DR, Taylor SR, Wheeler TM, Scardino PT. DNA ploidy by image analysis of individual foci of prostate cancer: a preliminary report. Cancer Res. 1991;51:4084-4089.

27. Koss LG, Melamed MR. Recognizing and classifying cells. In: Koss LG, Melamed MR (eds). Koss' Diagnostic Cytology, $5^{\text {th }}$ ed. Philadelphia: Lippincot Williams and Wilkins. 2006;119-120.

28. Werner M, Chott A, Fabiano A, Battifora H. Effect of formalin fixation and processing on immunohistochemistry. Am J Surg Pathol. 2000;24:1016-1019.

29. Creager AJ, Geisinger KR, Perrier ND et al. Intraoperative imprint cytologic evaluation of sentinel lymph nodes for lobular carcinoma of the breast. Ann Surg. 2004;239:61-66.

30. Cserni G. Effect of increasing the surface sampled by imprint cytology on the intraoperative assessment of axillary sentinel lymph nodes in breast cancer patients. Am Surg. 2003;69:419-423

31. Ozzello L, DeRosa C, Habif DV, Greene GL. An immunohistochemical evaluation of progesterone receptor in frozen sections, paraffin sections, and cytologic imprints of breast cascinomas. Cancer. 1991;67:455-462.

32. Aihara T, Munakata S, Morino H, Takatsuka Y. Touch imprint cytology and immunohistochemistry for assessment of sentinel lymph nodes in patients with breast cancer. Eur J Surg Oncol. 2003;29:845-848.

33. Aihara T, Munakata S, Morino H, Takatsuka Y. Comparison of frozen sections and touch imprint cytology for evaluation of sentinel lymph node metastasis in breast cancer. Ann Surg Oncol. 2004;11:747-750.

34. Flens MJ, van der Valk P, Tadema TM et al. The contribution of immunocytochemistry in diagnostic cytology. Comparisons and evaluation with immunohistology. Cancer. 1990;65:2704-2711.

35. Klevesath MB, Godwin RJ, Bannon R, Munthali L, Coveney E. Touch imprint cytology of core needle biopsy specimens: a useful method for immediate reporting of symptomatic breast lesions. Eur J Surg Oncol. 2005;31:490-494.

36. Sasaki M, Morimoti K, Koh M, Wakasa K, Haba T, Kinoshita $\mathrm{H}$. Cytologic diagnosis of estrogen and progesterone receptors in breast imprints. Acta Cytol. 2002;46:1056-1060.

37. Hsu SM. Immunohistochemistry. Methods Enzymol 1990; 184: 357-363.

38. Fortugno P, Wall NR, Giodini A et al. Survivin exists in immunochemically distinct subcellular pools and is involved in spindle microtubule function. J Cell Sci. 2002;115:575-585.

39. Li F, Ambrosini G, Chi EY et al. Control of apoptosis and mitotic spindle checkpoint by survivin. Nature. 1998;396:580-584.

40. Ferrandina G, Legge F, Martinelli E et al. Survivin expression in ovarian cancer and its correlation with clinicopathological, surgical and apoptosis-related parameters. Br J Cancer. 2005;92:271-277. 
41. Dong Y, Sui L, Watanabe Y, Sugimoto K, Tokuda M. Survivin expression in laryngeal squamous cell carcinomas and prognostic implications. Anticancer Res. 2002;22:2377-2384.

42. Altieri DC, Marchision C. Survivin apoptosis; an interloper between cell death and cell proliferation in cancer. Lab Invest. 1999; 79:1327-1333.

43. Grabowski P, Kuhnel T, Muhr-Wilkenshoff F et al. Prognostic value of nuclear survivin expression in oesophageal squamous cell carcinoma. Br J Cancer. 2003;88:115-119.

44. Moon WS, Tornawski AS. Nuclear translocation of suvivin in hepatocellular caricnoma: a key to cancer cell growth? Hum Pathol. 2003;34:1119-1126.

45. Kawasaki H, Toyoda M, Shinohara H. Expression of survivin correlates with apoptosis, proliferation and angiogenesis during human colorectal tumorigenesis. Cancer. 2001;91: 2026-2032.

46. Sui L, Dong Y, Ohno M. Survivin expression and its correlation with cell proliferation and prognosis in epithelial ovarian tumors. Int J Oncol. 2002;21:315-20.

47. Asanuma H, Torigoe T, Kamiguchi K et al. Survivin expression is regulated by coexpression of human epidermal growth factor receptor 2 and epidermal growth factor receptor via phosphatidylinositol 3-kinase/AKT signaling pathway in breast cancer cells. Cancer Res. 2005;65: 11018-11025.

48. Singh M, Bleile MJ, Shroyer AL, Heinz D, Jarboe EA, Shroyer KR. Analysis of surviving expression in a spectrum of benign to malignant lesions of the breast. Appl Immunohistochem Mol Morphol. 2004;12:296-304.
49. Ryan B, Konecny G, Kahiert S et al. Survivin expression in breast cancer predicts clinical outcome and is associated with HER2, VEGF, urokinase plasminogen activator and PAI-1. Annals of Oncology doli/o.1093/annonc/mdj121.2006.

50. Monzo M, Rosell R, Felip E et al. A novel anti-apoptosis gene: re-expression of survivin messenger RNA as a prognosis marker in non-small cell lung cancers. J Clin Oncol. 1999;17:2100-2104.

51. Kato J, Kuwabara Y, Mitani M et al. Expression of survivin in esophageal cancers: correlation with the prognosis response to chemotherapy. Int J Cancer. 2001;95:92-95.

52. Lopez M, Eberle F, Mattei MG et al. Complementary DNA characterization and chromosomal localization of a human gene related to the poliovirus receptor-encoding gene. Gene. 1995;155:261-265.

53. Reymond N, Borg JP, Lecocq E et al. Human nectin 3/PRR3: a novel member of the PVR/PRR/nectin family that interacts with afadin. Gene. 2000;255:347-355.

54. Letessier A, Garrido-Urbani S, Ginestier C et al. Correlated break at PARK 2/FRAGE and loss of AF-6/Afadin protein expression are associated with poor outcome in breast cancer. Oncogene. 2006;26:298-307.

55. Yoshida H, Ishiko O, Sumi T, Matsumoto Y, Ogita S. Survivin, bcl-2 and matrix metalloproteinase- 1 enhance progression of clear cell- and serous type ovarian cancers. Int J Oncol. 2001;19:537-542.

56. Zaffaroni N, Pennati M, Collela $\mathrm{G}$ et al. Expression of the anti-apoptotic gene survivin correlates with taxol resistance in human ovarian cancer. Cell Mol Life Sci. 2002;59:1406-1412.

Submitted: 2 May, 2010 Accepted after reviews: 31 January, 2011 